Florida International University FIU Digital Commons

11-10-2016

\title{
A Quantitative Investigation Exploring Illicit Drug Use Inside and Out of the Foodservice Industry
}

Kristen Kaminski

kkami005@fiu.edu

DOI: $10.25148 /$ etd.FIDC001197

Follow this and additional works at: https:// digitalcommons.fiu.edu/etd

Part of the Hospitality Administration and Management Commons

\section{Recommended Citation}

Kaminski, Kristen, "A Quantitative Investigation Exploring Illicit Drug Use Inside and Out of the Foodservice Industry" (2016). FIU Electronic Theses and Dissertations. 3036.

https://digitalcommons.fiu.edu/etd/3036 


\title{
FLORIDA INTERNATIONAL UNIVERSITY
}

Miami, Florida

\section{A QUANTITATIVE INVESTIGATION EXPLORING ILLICIT DRUG USE INSIDE AND OUT OF THE FOODSERVICE INDUSTRY}

\author{
A thesis submitted in partial fulfillment of \\ the requirements for the degree of \\ MASTER OF SCIENCE \\ in \\ HOSPITALITY MANAGEMENT \\ by \\ Kristen Kaminski
}

2016 
To: Dean Mike Hampton

School of Hospitality and Tourism Management

This thesis, written by Kristen Kaminski, and entitled A Quantitative Investigation Exploring Illicit Drug Use Inside and Out of the Foodservice Industry, having been approved in respect to style and intellectual content, is referred to you for judgment.

We have read this thesis and recommend that it be approved.

Eric Beckman

Barry Gump

Jinlin Zhao

Miranda Kitterlin, Major Professor

Date of Defense: November 10, 2016.

The thesis of Kristen Kaminski is approved.

Dean Mike Hampton

School of Hospitality and Tourism Management

Andrés G. Gil

Vice President for Research and Economic Development and Dean of the University Graduate School

Florida International University, 2016 
(C) Copyright 2016 by Kristen Kaminski

All rights reserved. 


\section{DEDICATION}

I dedicate this thesis to my phenomenal parents- I did it! 


\section{ACKNOWLEDGMENTS}

The completion of this thesis would not have been possible without the guidance and support of my remarkable committee members, Dr. Miranda Kitterlin, Dr. Jinlin Zhao, Dr. Eric Beckman, and Dr. Barry Gump. This journey has been an incredible experience that will resonate with me for years to come. Thank you all for dedicating some of your valuable time to accompany me on this academic adventure!

Dr. Kitterlin, words cannot express the magnitude of how grateful I am to have you as my thesis chair, professor, mentor, and dearest friend. You have been an inspiration to me from the moment I first met your acquaintance. I have the utmost respect and admiration for you. Working alongside you these past few years has truly been an honor. Thank you for believing in me.

I would like to extend a very special thanks to Professor Greg Bohan. Greg, thank you for having me as your TA and assigning me to the world's most difficult group- that truly was a turning point in my FIU career! I would also like to thank Master Sergeant Brittany Palmer, my supervisor in the Air Force. Brittany, your support through this entire process has meant the world to me. Thank you for understanding! To my coaches at Athletic Development and Performance Training, I can’t thank you enough for providing me with a healthy outlet to relieve stress and clear my head.

Last, but most certainly not least, thank you Mom and Dad for being my greatest support system and never giving up on me. I love you both to the moon and back. 


\title{
ABSTRACT OF THE THESIS \\ A QUANTITATIVE INVESTIGATION EXPLORING ILLICIT DRUG USE INSIDE AND OUT OF THE FOODSERVICE INDUSTRY
}

\author{
by \\ Kristen Kaminski \\ Florida International University, 2016 \\ Miami, Florida \\ Professor Miranda Kitterlin, Major Professor
}

The primary purpose of this study was to perform a follow-up quantitative investigation of foodservice employees' illicit drug use behaviors, experiences with illicit drug use prevention efforts, and perceived negative outcomes associated with illicit drug use as compared to the non-foodservice labor force. An online survey was designed for this study to collect data and independent t-tests were conducted to analyze the data and test the hypotheses. Results indicated foodservice employees are more likely to use illicit drugs and are more concerned with short-term negative outcomes as a result of illicit drug use than the non-foodservice labor force. Furthermore, illicit drug use prevention efforts are less prominent in the foodservice industry than in other workplaces. This study provides foodservice industry professionals with further insight regarding illicit drug use, and offers practical implications that may help mitigate this phenomenon. Keywords: Foodservice Industry, Employee Drug Use, Illicit Drug Use 
CHAPTER $\quad$ PAGE

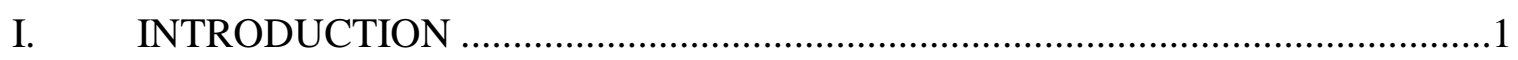

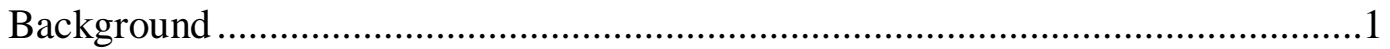

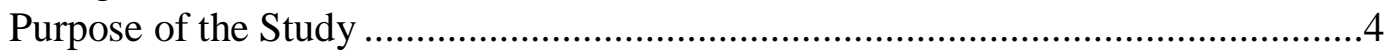

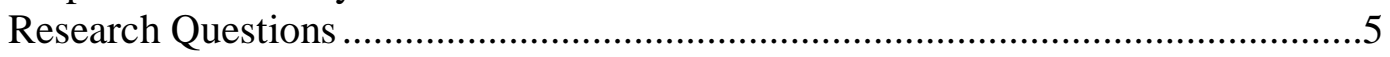

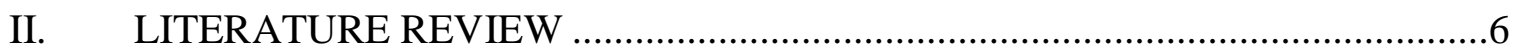

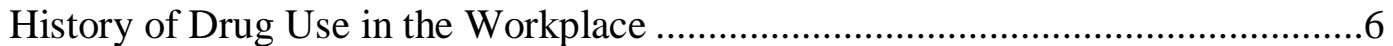

Why Drugs? (Origin of Drugs) .............................................................................

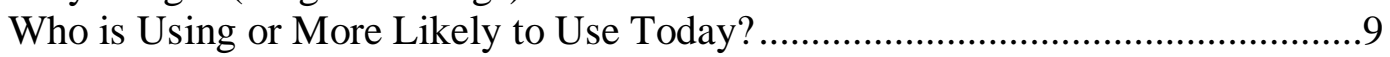

Illicit Drug Use in the Foodservice Industry.......................................................12

Attributing Factors to Illicit Drug Use ..........................................................14

Undesirable Workplace Behaviors ………………........................................18

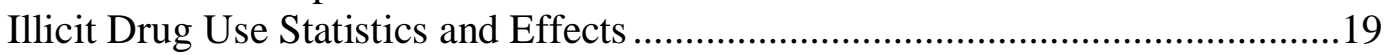

Perceived Consequences of Illicit Drug Use ......................................................22

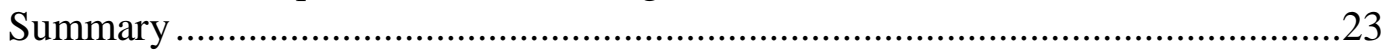

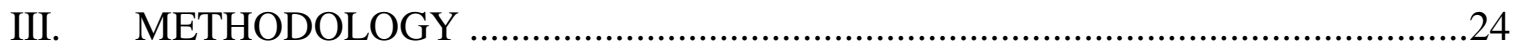

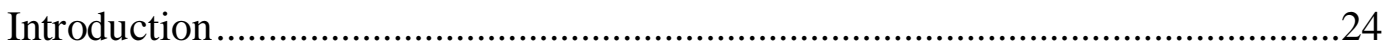

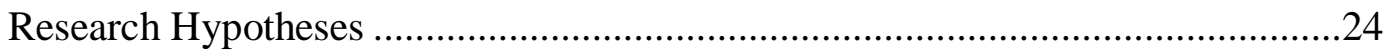

Research Design....................................................................................26

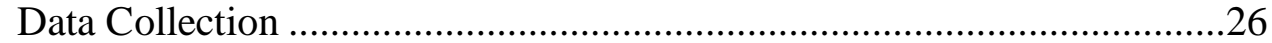

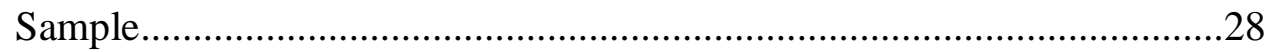

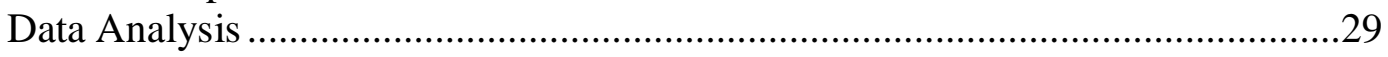

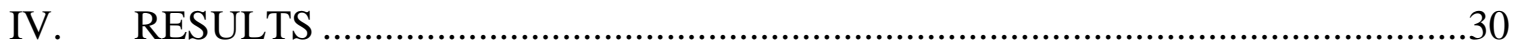

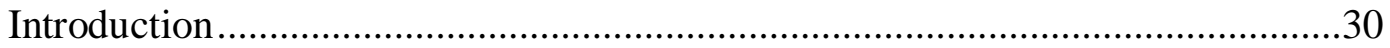

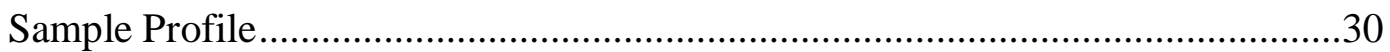

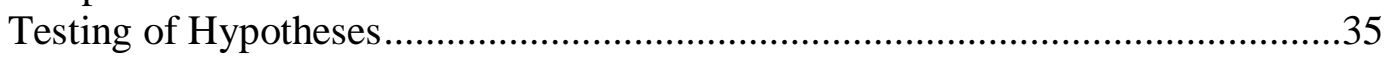

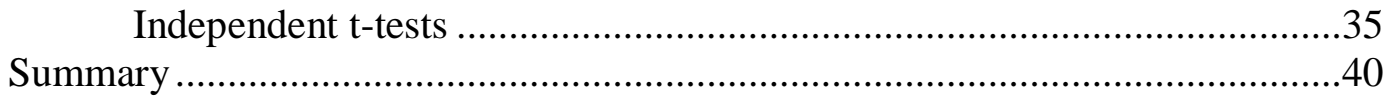

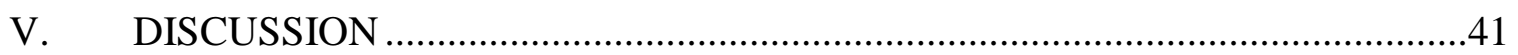

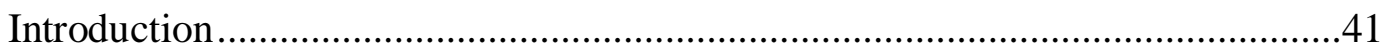

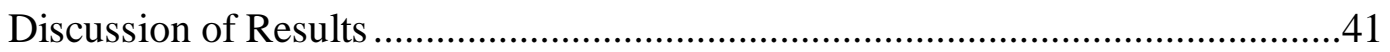

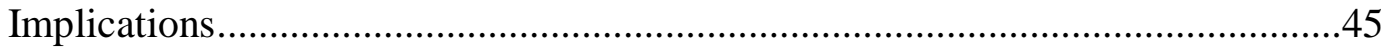

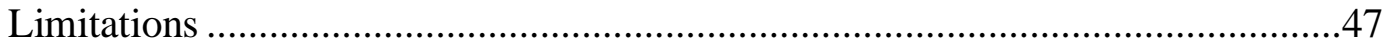

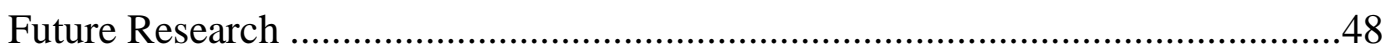

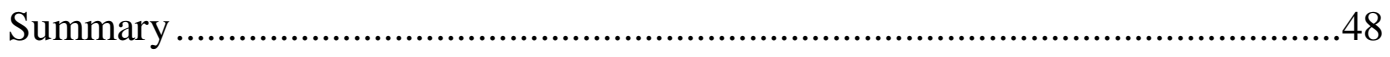

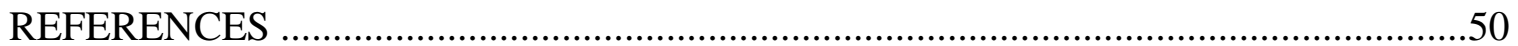




\section{LIST OF TABLES}

TABLE

PAGE

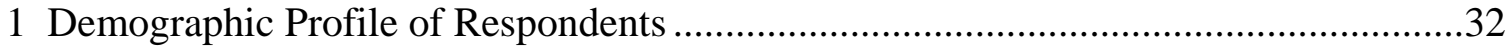

2 Demographic Profile of Foodservice vs. Non-Foodservice Respondents ....................33

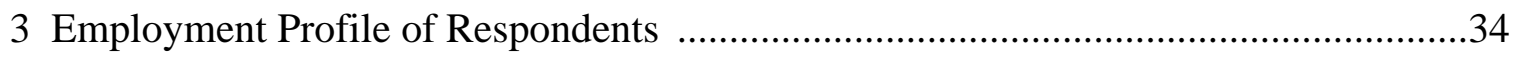

4 Differences in Mean Scores for Illicit Drug Use Behaviors ......................................36

5 Differences in Mean Scores for Illicit Drug Use Prevention Efforts ...........................37

6 Differences in Mean Scores for Illicit Drug Use Outcome Concerns .........................39 


\section{CHAPTER I \\ INTRODUCTION}

\section{Background}

With a workforce of approximately 14.4 million employees and sales projected to reach $\$ 782.7$ billion in 2016 (equating to 4 percent of the U.S. gross national product), 1 in 10 Americans are employed in the foodservice industry making it the nation's second largest private sector employer (National Restaurant Association, 2016). Moreover, the National Restaurant Association (2016) predicts the foodservice industry will be responsible for creating 16.1 million jobs by 2026. This is not surprising considering a survey conducted by Zagat (2016) found the national average for dining out is 4.5 times a week. Moreover, eating and drinking establishments reached $\$ 54.6$ billion in sales for the month of July 2016, with consumer spending projected to steadily increase (National Restaurant Association, 2016).

To keep up with consumer demand, foodservice employees put in long hours and are subject to shift work and overtime. This hard work is not always suitably reflected in one’s paycheck. According to the Bureau of Labor Statistics, the median hourly wage for food preparation and serving workers combined was $\$ 9.03$ and the annual median wage was $\$ 18,780$ in 2015. Approximately 2 in 5 of foodservice workers live in or near poverty and rarely receive fringe benefits (Shierholz, 2014).

In addition to being one of the nation's largest private sector employers, the foodservice industry leads all other U.S. industries in illicit drug use. Numerous studies have found that illicit drug consumption is prevalent in the foodservice industry and considerably higher among foodservice employees than in other industries (Belhassen \& 
Shani, 2012; Bush \& Lipari, 2015; “Drug use highest in foodservice”, 2007; Frone, 2006;

Kitterlin, Curtis, \& Cervera, 2015; Kitterlin, Moll, \& Kaminski, 2016; Murray, 2009;

Romeo, 2015; Substance Abuse and Mental Health Services Administration, 2009a, 2011, 2012, 2013, 2016; Zhu, Tews, \& Stafford, 2010; Zuber, 1997). According to the National Survey on Drug Use and Health (NSDUH), illicit drugs include marijuana, cocaine (including crack), heroin, hallucinogens, and inhalants, as well as the misuse of prescription pain relievers, tranquilizers, stimulants, and sedatives (SAMHSA, 2016). SAMHSA found that combined data from 2008-2012 revealed 8.6 percent of all full-time workers ages 18-64 employed in the United States used illicit drugs and 9.5 percent had a substance use disorder (Bush \& Limpari, 2015). Moreover, Bush and Limpari (2015) reported an illicit drug use rate of 19.1 percent and a substance use disorder rate of 16.9 percent among foodservice workers for 2008-2012.

Weber (2016) reported the number of U.S. workers testing positive for illicit drug use is at an all-time high. According to data gathered from Quest Diagnostics Inc., a leading provider of medical diagnostic testing, the number of positive tests yielded from general workforce drug testing rose from 4.1 percent in 2011 to 4.8 percent in 2015 (Weber, 2016). Findings from the Drug Testing Index (Quest Diagnostics, 2012) that tested 4.8 million samples from the general workforce revealed an overall increase in amphetamines, cocaine, oxycodone, and opiates positivity rates in 2011. Amphetamine positives were up 16.7 percent from 2010 and up 75 percent since 2007, cocaine positives rose 8 percent, oxycodone positives were up 10 percent from 2010 and up 25 percent since 2007, and opiate positivity rates rose 7.7 percent and increased by 20 percent since 2007. Quest data also found that marijuana was responsible for more than half of 
positive tests and the detection of heroin has increased. This increase in heroin detection supports the Centers for Disease Control and Prevention's claim that heroin use is on the rise among both men and women- from various age groups and income levels- across the United States (Centers for Disease Control and Prevention, 2016). The rise in heroin use echoes the CDC's findings that three out of four new heroin users reported abusing prescription opiates prior to using heroin.

Previous studies have found that illicit drug use has a detrimental impact on the workplace by adversely affecting productivity/performance, attendance, and safety (DiNardo, 1994; French, Zarkin, Hartwell, \& Bray, 1995; Frone, 2004; Martin, Kraft, \& Roman, 1994; Zhu et al., 2010). As reported by the National Institute on Drug Abuse (NIDA, n.d.), data from 1997 suggested it was likely for illicit drug users to have missed more than two work days in a month and to have been employed by more than three employers within a year. The prevalence of illicit drug use within the foodservice industry poses an organizational level threat. Larsen (1994) suggested that illicit drug use negatively effects service quality, profit and revenue. In addition, illicit drug use may jeopardize workplace interpersonal relationships (Bennett \& Lehman, 1999).

Not only is illicit drug use detrimental to the organization as a whole, but Horgan, Skwara, Strickler, and Anderson (2004) assert substance abuse to be the nation's leading health problem. It is common knowledge that illicit drug use can lead to a variety of adverse health effects. These health effects are categorized as acute toxic effects (e.g., overdose), acute effects of intoxication (e.g., accidental injury), development of dependence, chronic disease (e.g., cirrhosis), bacterial and viral infections, and mental disorders (Degenhardt \& Hall, 2012). According to the National Institute on Drug Abuse 
(NIDA, n.d.), roughly 460,000 deaths in the United States in the year 2000 were attributed to illicit drug use and smoking, and an estimated 40 million incapacitating illnesses or injuries are caused by tobacco, alcohol, or illicit drug use every year.

\section{Purpose of the Study}

Record-breaking illicit drug use and disorder rates, the multitude of health concerns, and the negative impact these are having on the food service industry warrant further investigation. In attempt to further explore this phenomenon, Kitterlin et al. (2016) conducted a qualitative study that examined illicit drug use behaviors of foodservice employees and the impact the foodservice work environment has on individuals’ drug use patterns as compared to the general labor force. Interviews were conducted with 14 full-time employed foodservices workers and 15 full-time individuals employed in other industries. Kitterlin et al. (2016) discovered four themes related to illicit drug use behavior among foodservice workers as compared to their general workforce population counterparts.

Themes that emerged were (1) Current Use Patterns, (2) Awareness of Substance Use Prevention Policies/Efforts (3) Perception of Attitudes among Co-Workers, and (4) Recognition of Negative Impacts. As reported in Kitterlin et al. (2016), foodservice employees indicated a higher rate of illicit drug usage compared to the general population. Foodservice employees also indicated their drug usage increased after beginning work in the industry, as a result of minimal prevention efforts (lack of enforcement) and the availability and ease of access of illicit drugs in the workplace (Kitterlin et al., 2016). Foodservice employees reported the presence of an accepted and 
prevalent culture of drug use, and they were more concerned with potential short-term negative consequences rather than long-term effects of using drugs (Kitterlin et al., 2016). The purpose of this study was to perform a follow-up quantitative investigation of the aforementioned themes.

Since it is not considered an illicit drug, it should be noted that alcohol is not reported in the scope of this manuscript. Illicit drug use refers to the use of marijuana, cocaine (including crack), heroin, hallucinogens, and inhalants, as well as the misuse of prescription pain relievers, tranquilizers, stimulants, and sedatives as defined by NSDUH (SAMHSA, 2016). Also, it should be noted that marijuana is included in this study as an illicit drug since it is not legalized nationwide.

\section{Research Questions}

Based on the findings of the qualitative study conducted by Kitterlin et al. (2016) and a review of the related literature, the following research questions were formed:

1. What are the illegal drug use behaviors of foodservice employees as compared to the non-foodservice labor force population?

2. What experiences do foodservice employees have with drug use or abuse prevention policies in comparison with the non-foodservice labor force population?

3. What outcomes do foodservice employees perceive to be associated with their drug use versus the non-foodservice labor force population? 


\section{CHAPTER II}

\section{LITERATURE REVIEW}

\section{History of Drug Use in the Workplace}

Historically, the use of alcohol and other psychoactive substances have been entangled with labor for roughly a thousand years (Frone, 2013). Chewing stimulants such as the cocoa leaf and areca nut wrapped in a betel leaf was common practice among laborers exposed to long hours and heavy, repetitive work prior to 1500 A.D. (Meyer \& Quenzer, 2005; Westmeyer, 1988; as cited in Frone, 2013). As the name suggests, stimulants excite the central nervous system and temporarily increase alertness, attention, and energy. It is no surprise that manual laborers in historical times turned to the use of stimulants to keep up with the demands of their work. Similarly, on-the-job alcohol consumption was deemed standard practice throughout preindustrial Europe and America. However, while alcohol was widely accepted as a pain reliever, reward, and partial payment for services rendered, intoxication which hindered work productivity was most certainly not condoned by employers. (Frone, 2013). As the $20^{\text {th }}$ century approached, advancements in technology and the emergence of workers' compensation laws changed the way employers viewed employee alcohol consumption (F.W.Taylor, 1915; Trice \& Schonbrunn, 1981; as cited in Frone, 2013). Moreover, concerns over illicit drug use became increasingly noteworthy by the $21^{\text {st }}$ century.

In addition to jeopardizing employee health, productivity, and safety, employee alcohol and drug use on or off the clock can produce an unnecessary financial burden for the national workforce (Frone, 2013). On September 15, 1986, President Ronald Reagan 
issued Executive Order 12564-Drug-Free Federal Workplace which imposed new guidelines for federal employees regarding illegal drug use. Under this order, federal employees are required to refrain from illegal drug use (both on and off duty), and drug testing became mandatory. Moreover, individuals who were found using drugs were deemed unfit for federal employment. As reported in Williams (1986), the White House's top advisers and the courts were skeptical of these new guidelines because expansive random drug testing was considered unconstitutional. However, the executive order was immediately put into effect to enforce the importance of a drug-free workplace. Two years later, the Drug-Free Workplace Act (1988) followed which "requires some federal contractors and all federal grantees to agree that they will provide drug-free workplaces as a condition of receiving a contract or grant from a federal agency”. If an employer covered under this act fails to comply with the requirements, the employer may be subject to harsh penalties resulting in possible suspension or termination of contracts or grants (“Drug-Free Workplace Act”, n.d.).

\section{Why Drugs? (Origin of Drugs)}

Drugs are deeply rooted in today's society. Not everyone uses or abuses them, but it is safe to say everyone around the world has heard of them. People of all ages, backgrounds, and cultures are familiar with drugs in one form or another. Drugs, drug usage, and their effects on individuals and society as a whole are controversial in their own rite. There is such a negative connotation attached to drugs that we tend to lose sight of why people started using them in the first place. The origins of drug use may have curiosity to blame. (Gahlinger, 2004). 
The inquisitiveness humans possess has led to countless discoveries since the beginning of time. Curiosity and experimentation may most likely be responsible for the discovery of mind-altering substances. The fossilized remains of ten Neanderthals unearthed in the Shanidar cave located in present day Iraq suggested drugs were used well before the evolution of modern humans (Ferner, 2014; Gahlinger, 2004). As reported in Ferner (2014), evidence of a variety of plants known for their medicinal properties were found at Shanidar. Guerra-Doce (2015) noted pieces of opium poppy were found in the teeth of an adult male discovered at a Neolithic site in Spain, bowls containing charred cannabis seeds were found at an archaeological site in Romania, and a host of plant species containing psychoactive properties were discovered in a number of prehistoric sites throughout Europe.

Consumption of psychoactive plants brought about various feelings and effectsrelaxation, happiness, drowsiness, increased alertness, increased energy, increased stamina, strange sensations, terrifying visions, or profound awareness were among those experienced (Gahlinger, 2004). Drugs that healed, prevented disease, or had an overall positive effect were regarded as sacred, while drugs that caused harm, induced pain, or had an overall negative effect were considered poison (Gahlinger, 2004). However, it is important to note that any substance consumed in excess can have severe, even lethal, consequences. Moreover, psychoactive substances played a vital role in religion and have always been closely linked to ritual usage; traces of mind-altering substances are primarily found in tombs and ceremonial locations (Gahlinger, 2004; Guerra-Doce, 2015). Drugs, whether used for hedonistic, social, religious, or medicinal purposes, are very much integrated in the human experience (Gahlinger, 2004). 


\section{Who is Using or More Likely to Use Today?}

Not everyone in today's world is addicted to drugs. In fact, contrary to popular belief, there are some people who have never even tried or thought about trying an illegal substance. So, why are some people more likely to use or abuse drugs than others? Since no two people are exactly alike, it is difficult to determine what exactly causes one person to be more prone to drug use (addiction) than others. However, there are a few basic risk factors that may increase the propensity of drug use or addiction. Risk factors are defined by the Substance Abuse and Mental Health Services Administration (2015) as characteristics at the biological, psychological, family, community, or cultural level that precede and are associated with a higher likelihood of negative outcomes. In other words, family history, genetics, personality traits, mental health disorders, and the environment can all play a role in whether or not a person will use or develop an addiction to drugs.

Drug addiction most likely involves genetic predisposition; children of parents who abuse drugs or alcohol are more likely to develop an addiction (Mayo Clinic, 2014). According to the National Institute on Alcohol Abuse and Alcoholism (NIAAA, 2008), children of drug abusing parents are 45 to 79 percent more likely to abuse drugs themselves than the general population. However, it is important to note that the environment in which a child was raised, may play a strong role, as well.

Previous research has found that men were more likely than women to have problems with drugs and alcohol (Mayo Clinic, 2014; NIAAA, 2008; SAMHSA, 2016). Young adults aged 18-24 were found to have the highest rates of drug and alcohol abuse (NIAAA, 2008), and a 2014 study found young adults aged 18-25 were the biggest 
abusers of prescription drugs, particularly opioid pain relievers, ADHD stimulants, and anti-anxiety medications (National Institute on Drug Abuse, 2016). Family dysfunction, peer pressure, neighborhood poverty and violence may be to blame (SAMHSA, 2016).

Mental illness is another risk factor that increases the likelihood of drug use (Mayo Clinic, 2014; National Survey on Drug Use and Health, 2010; SAMHSA, 2016). According to the NSDUH (2010), findings revealed 25.8 percent of illicit substance users aged 18 or older had a mental illness in the past year versus 12.1 percent who did not have a mental illness in the past year. The study also found that among the 20.3 million adults aged 18 or older who had a substance abuse disorder in the past year, 45.1 percent (9.2 million adults) had a co-occurring mental illness (NSDUH, 2010).

While little research has been done examining the relationship between intelligence and drug use, White and Batty (2011) conducted a longitudinal study with data collected from a 1970 British Cohort Study to determine if high childhood intelligent quotient (IQ) scores were linked to illegal drug use later in life. Findings of the study suggest children with high IQ may have an increased risk of illegal drug use in adolescence and adulthood (White \& Batty, 2011). Another study conducted by White, Gale, and Batty (2012) which followed members of the 1958 National Child Development Survey also found a link between high childhood IQ and illegal drug use in adulthood.

White and Batty (2011) postulate that the reasoning behind the findings may be that people with higher IQ's have the ability to intellectualize and tend to be open to new experiences and sensation seeking. IQ tests lacks cultural variability and emotional intelligence, creativity, the ability to make decisions and the use of common sense are not 
measured by IQ testing (Bon, 2014). Moreover, Bon (2014) points out that the British Cohort study did not contain drug use patterns so an association between high IQ, low emotional intelligence, and drug use may be difficult to determine.

As defined by Goleman (1995) and Riley and Schutte (2003), “emotional intelligence (EI) is the ability to adoptively perceive, understand, regulate, and harness emotions in the self and in others” (p. 391); the skill set to cope with challenges and achieve success. Numerous studies have linked low emotional intelligence to drug abuse (Khanmohammadi, Homayouni, Amiri, \& Nikpour, 2009; Kun \& Demetrovics, 2010; Manoj Sharma, 2012; Mayer, Salovey, \& Caruso, 2004; Riley \& Schutte, 2003). However, a person with high emotional intelligence may better perceive, use, and manage emotions, and are less likely to engage in self-destructive behaviors (Mayer et al., 2004). It is important to note for the sake of this manuscript's topic, Cherniss (2000, as cited in Mayer et al., 2004), affirms EI provides the foundation for important competencies relevant to most jobs. EI plays an important role among workers who are in direct contact with customers as it positively contributes to job performance when there is a personal commitment to success (Mayer et al., 2004).

Previous studies have found there to be a high comorbidity of mental illness with drug use, indicating the need for mood, anxiety and personality disorders to be closely examined (Mayo Clinic, 2014; NSDUH, 2010; SAMHSA, 2016; Terracciano, Lockenhoff, Crum, Bienvenu, \& Costa, 2008). Personality traits need to be considered when discussing drug use since they are regarded as risk factors (Terracciano et al., 2008). What personality traits are drug users and abusers most likely to possess? Do these traits differ between drug of choice? Using the Five-Factor Model of personality which 
includes: Openness to Experience; Conscientiousness; Extraversion; Agreeableness; and Neuroticism, (Terracciano et. al, 2008) found marijuana users scored high on Openness and had low scores on Agreeableness and Conscientiousness, while cocaine and heroin users had high scores on Neuroticism and low on Conscientiousness, and high scores of

excitement-seeking were consistently associated with all types of drug users. Adults with substance abuse disorders also scored high on Neuroticism and low on Conscientiousness in a study conducted by Kotov, Gamez, Schmidt, and Watson (2010). These findings suggest that drug users and abusers are more likely to experience negative emotions such as anxiety, anger, and depression, and are more likely to be unorganized, unreliable, immoral, impulsive, and prone to deviant behavior (Terracciano et al., 2004). Ersche, Turton, Pradhan, Bullmore, and Robbins (2010) found individuals who are dependent on cocaine or amphetamines reported high levels of impulsivity and sensation-seeking.

\section{Illicit Drug Use in the Foodservice Industry}

While illicit drug and alcohol use have been native to the U.S. work force for countless years, the food service industry has been noted to be the ranking leader among U.S. industries to exhibit the highest incidence of employee illicit drug use (SAMHSA, 2009a; Bush \& Lipari, 2015; Romeo, 2015). Moreover, as reported in Bush \& Lipari (2015), SAMHSA estimated one out of every five full-time food service employees admitted to using illicit drugs between 2008 and 2012; a 4\% increase from the 2002-2004 report (which was 1 out of 6). Pidd, Roche, and Buisman-Pijlman (2011) found that hospitality workers were 3 times more likely than those working in other industries to use 
drugs at work, and Frone (2006) found restaurant workers were 9 times more likely to already be under the influence of drugs or alcohol when they show up to work.

In a more popularized account, Celebrity Chef Anthony Bourdain detailed his journey of over 25 years working in the restaurant industry which was riddled with drugs and alcohol in his memoir Kitchen Confidential (2007). Bourdain (2007) was an avid drinker and user of heroin, marijuana, cocaine, and other substances during his days as a chef in New York. One of the biggest names in the Miami restaurant scene, Chef Jonathan Eismann, sabotaged his successful career in October 2012 when he fled the scene of a car accident that killed a pedestrian. As reported in Kane ( 18 March, 2013), Eismann openly discussed drug use among chefs and the kitchen staff at the South Beach Wine and Food Festival, stating that throughout different times of the night "the potheads would cut themselves, the cokeheads were a disaster, and the junkies stood like stone statues at their stations”. Celebrity Chef John Higgins suggested in Kane (18 March, 2013) that sensitive, creative people are drawn to culinary jobs and attributed addiction in the kitchen to "long hours, an adrenaline rush, the pressure of quickly producing a quality product in a short time, and the accessibility to alcohol”. French Chef Marc Thuet nearly over-dosed several times during his 30 years of marijuana, heroin, opium, cocaine, OxyContin, and alcohol abuse (Kane, 2013). Thuet admitted he was obsessive, compulsive, and depressed which led him to years of self-medication through drugs and alcohol (Kane, 2013).

These personal accounts of drug abuse, along with numerous research studies, reaffirm the prevalence of substance abuse in the foodservice industry is no laughing 
matter. SAMSHA data exhibited a variation of substance use rates across industry groupings (Bush \& Lipari, 2015). The mining industry had the highest past month heavy alcohol use rate of 17.5 percent compared to the 4.4 percent of health care and social assistance employees and, as mentioned earlier, the accommodations and foodservice industry had the highest past month drug use rate of 19.1 percent as compared to the 4.3 percent of public assistance workers (Bush \& Lipari, 2015). Staggering differences in substance use rates suggest the work environment may influence substance use behaviors and establish norms (Ames, Grube, \& Moore, 2000).

\section{Attributing Factors to Illicit Drug Use}

Several factors can be attributed to the overindulgence of drugs and alcohol in the foodservice industry. A relatively young labor pool of workers aged 18-25 make up a large portion of foodservice employees and are among the highest abusers of drugs and alcohol (Belhassen \& Shani, 2012; Bennett, Aden, Broome, Mitchell, \& Rigdon, 2010; Kitterlin et al., 2015; Kitterlin et al., 2016; NIAAA, 2008). Erratic work schedules comprised of long hours, overtime, weekend and late-night shifts are all too common within the industry and likely to facilitate excessive consumption (Kitterlin et al., 2015; Kitterlin et al., 2016; Larsen, 1994; Spector, 2001). Moreover, Zhu (2008) found that bartending, working multiple jobs, and tip-earning positions are related to elevated substance use which further supports this claim.

A work culture of permissive norms, such as having a few drinks after a shift or going out after work, has been found to be highly influential in regards to substance use (Bacharach, Bamberger, \& Sonnenstuhl, 2002; Belhassen \& Shani, 2012; Kitterlin et al., 
2015; Kitterlin et al., 2016; Kjaerheim, Mykletun, Asland, Haldorsen, \& Anderson, 1995;

Kjaerheim, Mykletun, \& Haldorsen, 1996; Moore, Ames, Duke, \& Cunradi, 2012; Zhu et al., 2011). These workplace norms are essentially unwritten rules that deem certain attitudes and behaviors acceptable; all of which provide employees with a mutual understanding of the belief system present in that particular organization (Zhu, et al., 2010). All of the participants in Kitterlin et al. (2016) indicated that illicit drug use in the foodservice industry was an acceptable culture norm and a means to cope with the demand of the job. Moreover, Kitterlin et al. (2015) emphasized substance use is regarded as an integral part of the work environment.

Not only does the hospitality industry as a whole hold a low socio-economic position, but it cultivates a work environment brimming with immoral and deviant behavior (Miller, 1978; Shamir, 1981; Wood, 1992; as cited in Belhassen \& Shani, 2012). Since the foodservice industry is known to be synonymous with a substance using culture, Zhu et al. (2010) proposed that individuals who use illicit substances may actually self-select into the foodservice industry. Previous use patterns of binging on alcohol and marijuana increased the likelihood of that individual seeking out employment in the foodservice industry (Zhu, 2008). Previous studies have suggested that employees introduced into a work environment where excessive consumption of drugs and alcohol are displayed, are more likely to partake in heavy substance use as well (Kjaerheim et al., 1995; Kjaerheim, et al., 1996; Larsen, 1994).

Since the hospitality industry is comprised largely, in part, of bars and food service establishments, alcohol is readily available. Zhu et al. (2010) suggest that the prevalence and severity of substance use will be more substantial when substances are 
easily obtainable. Kitterlin et al. (2016) found that foodservice employees attributed an increase in drug usage to availability and ease of access. Since the propensity to spend is much greater when cash is in hand (Fudenberg \& Levine, 2006, as cited in Zhu et al., 2010) and economic resources are low (Deaton, 1992; Vohs \& Faber, 2007, as cited in Zhu et al., 2010), tipped employees may be more likely to spend on drugs and alcohol, especially when they are so readily available. Impulsivity also plays a role in spending and drug use; Chamorro, Bernardi, Potenza, Grant, Marsh, Wang, and Blanco (2012) found that impulsivity was common among males and younger individuals, and had an association with drug dependence and self-destructive behaviors such as engaging in activities without considering consequences or excessive spending.

Lenient attitudes, the lack of reinforcement of drug policies, and the cost of drug testing may also contribute to the illicit drug use problem that has plagued the foodservice industry. According to Hickox (2012), approximately 54 million workers employed full time indicated their employers conducted some sort of drug test in a national study conducted in 2010. Pre-employment drug testing was reported by 42.9 percent of employees and 29.6 percent reported random drug tests were conducted (Hickox, 2012). There is a long-standing association with illicit drug use and deviant behavior; illicit drug use presents a threat to the individual and society as a whole (Gahlinger, 2004). Hickox (2012) suggested that the prevalence of drug testing among particular employers may be a means of addressing the immorality of employee drug use. As previously stated, illicit drug use is a workplace norm and embedded in the culture of the foodservice industry (Bourdain, 2007; Kitterlin, et al., 2015; Kitterlin et al., 2016; Kjaerheim et al., 1995; Kjaerheim et al., 1996; Larsen, 1994; Zhu et al., 2011). It 
stands to reason that management is more likely to turn a blind eye towards drug use or an employee under the influence of an illicit substance (while at work) since it is an acceptable behavior among peers. Kitterlin et al. (2016) found that foodservice employees indicated little to no awareness of drug prevention policies at their place of employment, other than a blurb in the employee handbook stating illegal drug use is prohibited. Moreover, there was no enforcement of drug policies other than the occasional screening in the event of a workplace accident or injury (Kitterlin et al., 2016). Random drug testing is more likely to occur in larger organizations that employ 500+ employees and was found to be more common in the transportation and material-moving, production, and installation, maintenance and repair industries (Hickox, 2012).

Due to time restraints and high cost, employers in the United States will conduct drug testing under certain circumstances such as “pre-employment, random, postaccident, reasonable suspicion, and as a follow-up to rehabilitation” (Kitterlin \& Moreo, 2012, p.39). The cost of a drug test includes collection, laboratory testing, and medical review, and can range anywhere between $\$ 13$ and \$70 per test (Kitterlin \& Moreo, 2012). A safe and productive work environment is considered by the foodservice industry to be promoted through the use of pre-employment drug-testing since it may help to deter drug use (Kitterlin \& Moreo, 2012). However, pre-employment drug-testing inflicts a large financial burden on the foodservice industry; each pre-employment test averages $\$ 13$ to \$25 and an estimated turnover rate of 83 to 119 percent occurs on an annual basis (Kitterlin \& Moreo, 2012). 


\section{Undesirable Workplace Behaviors}

Numerous studies consider there to be an elevated risk of alcohol and drug abuse while at work and after work in the foodservice industry (Larsen, 1994; Leigh and Jiang, 1993; Mandell, Eaton, Anthony, \& Garrison, 1992; Stinson, DeBakey, \& Steffens, 1992; Zhiwei \& Snizek, 2003). Mangione and Quinn (1975) found that drug use at work and a decrease in productivity were significantly related to job satisfaction among a subsample of men, 30 years of age or older. In addition, SAMHSA (as cited in Belhassen \& Shani, 2012), reported the United States experienced an $\$ 81$ billion loss in productivity due to problems, such as tiredness and difficulties in concentration, related to alcohol and illicit drug use. Moreover, employees who use drugs are "3.6 times more likely to be involved in workplace accidents and 5 times more likely to file workers’ compensation claims” (Kaestner \& Grossman, 1998; SAMHSA, 2009; as cited in Belhassen \& Shani, 2012, p. 1293).

According to Belhassen and Shani (2012), employees who use drugs and alcohol are more likely to bring their problems to work. Moreover, the National Drug-Free Workplace Alliance (NDWA, 2007) attests that 80 percent of illicit drug users steal from their place of employment and substance abuse is the third leading cause of violence in the workplace. Employee absenteeism (Bacharach, Biron, \& Bamberger, 2010) and turnover (Bonn \& Forbringer, 1992; Iverson \& Deery, 1997) is a well-known problem in the hospitality industry; substance use has been shown to increase the rates of workplace absenteeism and turnover (Bacharach et al., 2010). Employees who use drugs are 10 times more likely than non-using employees to miss work and are responsible for three times the cost of health care (Hickox, 2012). 


\section{Illicit Drug Use Statistics and Effects}

Illicit drugs have various side effects that vary on an individual basis (from person to person). Moreover, Belhassen and Shani (2012) emphasize that is common for substance users to simultaneously use more than one substance at any given time. As a result, more serious side effects may occur. Findings from an Australian study conducted by Bywood, Pidd, and Roche (2006) revealed marijuana was the drug of choice, followed by ecstasy, amphetamines, painkillers, and cocaine across all occupational industries in 2004. Moreover, the study revealed that the hospitality industry was the leading industry of all types of drug use. More recently, 2010-2011 SAMHSA data reported the foodservice industry led all other occupational industries in substance use with 18.6 percent of workers using stimulants (Fricke, 2015). Moreover, as reported in Fricke (2015), the foodservice industry also placed first in 6 out of 10 substance categories and was measured by the number of standard deviations from the average rate of use: stimulants (3.82); tranquilizers (3.60); cocaine (3.33); marijuana (3.30); painkillers (3.26); and alcohol (2.46). These results echo the findings of numerous studies that suggest illicit drug use is most prevalent in the foodservice industry.

An estimated 22.2 million young adults aged 12 and older were reported by the National Survey on Drug Use and Health (NSDUH) to be current users of marijuana in 2014 (SAMHSA, 2015). Of those users, approximately 6.8 million were aged 18-25 (which corresponds to approximately 1 out of 5 young adults) and 13.5 million users were aged 26 and older (SAMHSA, 2015). When used alone, common negative side effects of marijuana include "feelings of anxiety, depression, fatigue, lack of motivation, low energy, lower alertness, slower response, memory problems, and psychomotor 
slowing” (Belhassen \& Shani, 2012, p. 1293). Kuhn, Swartzwelder, and Wilson (2008) affirm that the high obtained from marijuana is subjective and varies greatly among individuals, but is reported to be "intellectually interesting" and/or "emotionally pleasing” (p. 155). However, it is important to note that people are significantly less able to retain new information while under the influence of marijuana and the ability to effectively solve problems becomes hindered (Kuhn et al., 2008).

Data from the NSDUH (2014) revealed that 1.5 million people aged 12 and older were current users of cocaine (including 354,000 using crack), and 1.4 percent of adults aged 18 to 25 were among those users (SAMHSA, 2015). When taken in small doses, the user may experience feelings of euphoria, and may be more energetic, talkative, mentally alert and able to more quickly complete tasks (NIDA, 2016). On the other hand, cocaine use may cause an elevated level in body temperature, heart rate, and blood pressure, and may lead to erratic and violent behavior (NIDA, 2016). Moreover, NIDA (2016) suggests cocaine users may feel restless, irritable, anxious, and/or paranoid.

Data from the NSDUH (2014) revealed that an estimated 1.6 million young adults aged 12 or older were current non-medical users of stimulants (including 569,000 using methamphetamine), and 1.2 percent of adults aged $18-25$ were among those users (SAMHSA, 2015). Adderall, Ritalin, and Dextroamphetamine are the most commonly abused prescription medications and have a high rate of non-medical use (NIDA, 2014). The most common effects of non-medical use of stimulants are euphoria and pleasure, an increase in energy and alertness, and a decrease in appetite and the need for sleep (NIDA, 2014). However, long term use has the increased potential to cause tolerance and 
dependence which can lead to overdose, panic attacks, heart problems, or mental instability (“Effects of Stimulants”, n.d.).

Data from the NSDUH (2014) revealed that approximately 1.9 million young adults aged 12 or older were current non-medical users of tranquilizers (or barbituates), and 1.2 percent of adults aged 18-25 were among those users (SAMHSA, 2015). Tranquilizers are highly addictive and are often abused. Tranquilizers have a therapeutic effect which produces a sense of relaxation and are frequently used to treat anxiety and insomnia, but can also create feelings of euphoria when abused (Kuhn et al., 2008). However, fatal respiratory suppression or heart failure may result if taken with another type of sedating drug, including alcohol or opiates (Kuhn et al., 2008).

Approximately 4.3 million people aged 12 or older were current non-medical users of pain relievers, and 2.8 percent of young adults aged 18 to 25 were among those users according to the NSDUH (2014) data (SAMHSA, 2015). Moreover, there are approximately 26.4 million to 36 million opiate abusers and addicts worldwide (Volkow, 2014). The current prescription pain reliever abuse problem may be attributed to several factors including, "the drastic increase in the number of prescriptions written and dispensed, greater social acceptability for using medications for different purposes, and aggressive marketing by pharmaceutical companies”, (Volkow, 2014, para. 4).

Opiates slow breathing, produce a dreamy, euphoric state and decrease pain sensitivity (Kuhn et al., 2008), and are popular around the world due to their medicinal properties and recreational usage (Gahlinger, 2004). Common negative side effects include nausea, vomiting, and constipation. However, it is important to note that opiates are extremely dangerous when taken with other drugs that facilitate respiratory 
suppression; opiates are highly addictive and a lethal overdose can happen the first time (Kuhn et al., 2008). Prescription opiates such as Hydrocodone (e.g. Lortab, Vicodin) and Oxycodone (e.g. OxyContin, Percocet) are the most widely abused; abuse of prescription opiates is considerably higher than illegally synthesized drugs such as heroin (Gahlinger, 2004). However, in light of the nation's recent efforts to crack down on prescription opiate abuse, the Centers for Disease Control and Prevention (CDC) has noted a significant increase in the use of heroin (Centers for Disease Control and Prevention, 2016). Approximately 3 out of 4 new heroin users reported prescription opiate abuse prior to their heroin use (CDC, 2016).

\section{Perceived Consequences of Illicit Drug Use}

Not only does drug use take a toll on the organization, but it may adversely affect the health and well-being of the employee. With drug use so prevalent (and potentially fatal) in the foodservice industry, are employees even concerned about the possible side effects or consequences of illicit drug use? While both foodservice and non-foodservice

participants acknowledged negative effects of illicit drug use, Kitterlin et al. (2016) found that foodservice participants were more concerned with negative short-term effects of illicit drug use, such as hangovers, loss of focus, and lethargy, as compared to their nonfoodservice counterparts who focused more on the negative long-term effects such as addiction, financial burdens, and terminal health problems. Positive effects of illicit drug use such as euphoria, relaxation, enlightenment, and stress relief were indicated by both groups (Kitterlin et al., 2016). Few studies have been conducted to further examine this quandary. 


\section{Summary}

The literature provides evidence that illicit drug use can yield numerous adverse health effects, a variety of undesirable behaviors in the workplace, and wreak havoc across the food service industry. Food and beverage industry employees display higher rates of drug use than employees in other industries. Illicit drug use has been and continues to be an ongoing problem, with no permanent solution in sight. This raises the questions, "What are the illicit drug use behaviors of adults working in the foodservice industry?” and “What is being done to alleviate drug abuse behaviors?” Based on a thorough literature review, and the purpose of the study, the following research questions were developed:

1. What are the illegal drug use behaviors of foodservice employees as compared to the non-foodservice labor force?

2. What experiences do foodservice employees have with drug use or abuse prevention policies in comparison with the non-foodservice labor force?

3. What outcomes do foodservice employees perceive to be associated with their drug use versus the non-foodservice labor force? 


\section{CHAPTER III \\ METHODOLOGY \\ Introduction}

This study is a continuation of previous qualitative research which found emergent themes regarding illicit drug use among foodservice workers that included current use patterns, awareness of prevention policies/efforts, perception of attitudes among co-workers, and recognition of negative impacts (Kitterlin et al., 2016). Since Kitterlin et al. (2016) exclusively explored illicit drug use among foodservice workers, generalizations could not be made. This current study used a survey of a larger sample to investigate the validity of the findings. In Phase I (Interview Phase), interviews were conducted in order to launch a qualitative investigation of food service worker drug use. In Phase II (Survey Phase), surveys were conducted in order to quantitatively confirm themes derived from the interview phase.

\section{Research Hypotheses}

The findings of the literature review suggest that illicit drug consumption is not only prevalent in the foodservice industry, but usage is much higher among foodservice employees than those working in other industries (Belhassen \& Shani, 2012; Bush \& Lipari, 2015; “Drug use highest in foodservice”, 2007; Frone, 2006; Kitterlin et al., 2015; Kitterlin et al., 2016; Murray, 2009; Romeo, 2015; Substance Abuse and Mental Health Services Administration, 2009a, 2011, 2012, 2013, 2016; Zhu et al., 2010; Zuber, 1997). Approximately one out of every five full-time foodservice employees admitted they were using illicit drugs between 2008 and 2012 as reported by SAMHSA (Bush \& Lipari, 2015). Moreover, hospitality workers were 3 times more likely to use 
illicit drugs at work than those working in other industries (Pidd et al., 2011). It is also suggested that foodservice workers are 9 times more likely to be under the influence of drugs or alcohol when they report to work (Frone, 2006). Therefore, it is hypothesized that foodservice employees use illicit drugs more than the non-foodservice labor force. Thus, Hypothesis 1 was formed:

H1: Foodservice employees use illicit drugs more than the non-foodservice labor force.

The findings of the literature suggest illicit drug use in the foodservice industry is considered to be part of the workplace culture (Kitterlin et al., 2015; Kitterlin et al., 2016; Kjaerheim et al., 1995; Kjaerheim et al., 1996; Larsen, 1994; Zhu et al., 2011). A variation of substance use rates was found across industry groupings in SAMHSA data which suggests the work environment may influence substance use behaviors and establish norms (Ames et al., 2000); the accommodations and foodservice industry had the highest past month drug use rate of 19.1 percent (Bush \& Lipari, 2015). The data from the Drug Testing Index revealed an overall increase in positivity rates for amphetamines, cocaine, oxycodone, and opiates in approximately 4.8 million samples from the overall workforce in 2011 (Quest Diagnostics, 2012). Moreover, foodservice employees indicated little to no awareness of drug prevention policies or efforts at their workplace (Kitterlin et al., 2016). It is hypothesized that illicit drug use prevention efforts (e.g. random drug testing) for foodservice employees are less prominent than in other workplaces. Thus, Hypothesis 2 was formed: 
H2: Illicit drug use prevention efforts (e.g. random drug testing) for foodservice employees are less prominent than for the non-foodservice labor force.

The findings of the literature suggest that illicit drug use adversely effects productivity, performance, attendance, interpersonal relationships, and safety in the workplace (Bennett \& Lehman, 1999; DiNardo, 1994; French et al., 1995; Frone, 2004; Martin et al., 1994; Zhu et al., 2010). Moreover, approximately 40 million debilitating illnesses and injuries are the result of substance use on an annual basis (National Institute on Drug Abuse, n.d.). However, foodservice employees were more concerned with short-term negative outcomes, such as hangovers and lethargy, as opposed to long-term effects, such as acute disease as a result of illicit drug use (Kitterlin et al., 2016). It is hypothesized that there are more short-term negative outcome concerns regarding drug use among foodservice employees as compared to the general labor force population. Thus, Hypothesis 3 was formed:

H3: There are more short-term negative outcome concerns regarding drug use among foodservice employees than the non-foodservice labor force.

\section{Research Design}

\section{Data Collection}

\section{Survey Phase.}

An anonymous online 25-item survey conducted electronically using Qualtrics which took a maximum of 15 minutes to complete was created by the researcher based on previous research (Kitterlin et al., 2016) and a thorough review of the literature. Prior to launching the survey, pilot test was conducted with eight hospitality graduate students 
and three university professors from Florida International University; these were not included in the final sample. Afterwards, each survey item was discussed as to how well the participant was able to understand the item. The survey was slightly modified in response to pilot feedback, and consisted of five main sections: 1) demographic information, 2) drug use patterns, 3) drug policy and prevention efforts, 4) drug accessibility and perceived attitudes among employees regarding drug use, and 5) outcome concerns regarding drug use.

The first section consisted of nine items related to demographics: gender, age, ethnicity (race), employment status, hours worked, occupation, income, and education level. Items 10-17, questions related to drug use patterns during the past 30 days, were derived from the DAST-20 (Skinner, 1982) and the Phase I interviews from previous research (Kitterlin et al., 2016). Items 18-22, questions related to awareness of illicit drug use workplace policies and preventions, were derived from the Phase I interviews (Kitterlin et al., 2016). Items 23-24, questions related to illicit drug accessibility and perception of attitudes among co-workers regarding illicit drug use, were derived from the Phase I interviews (Kitterlin et al., 2016). An ordinal scale was utilized for item 25 to determine rate of outcome concern regarding drug use $(1=$ not concerned to $5=$ very concerned). A combination of short-term and long-term outcome concerns were listed. The following outcome concerns, in no particular order, were derived from the Phase I interviews (Kitterlin et al., 2016): anxiety, addiction, withdrawals, loss of job, loss of focus at work, making bad choices, dangerous situations, fear of overdose, paranoia, legal issues, lethargy, less productive, financial burden/cost of drugs, overdose, health problems, anger/aggression/violence. The following outcome concerns, in no particular 
order, were derived from the pilot test: conflict with friends/family, bad batch of drugs, domestic abuse, hangover. The following outcome concerns, in no particular order, were derived from previous literature: birth defects (NIDA, 2015), loss of friends/family, uncertainty of long-term goals (Newcomb \& Bentler, 1988), intense hallucinations (Poole \& Brabbins, 1996), sexual assault (Newcomb \& Bentler, 1988; Winters \& Henly, 1989), physical appearance harmed/changed, damaged reputation (Blanchard, Morgenstern, Morgan, Lobouvie, \& Bux, 2003), injury (Madan, Beech, \& Flint, 2001), drug use is wrong, career indecision (Kandel, 1978), weight gain/weight loss (Greenberg, Kuehnle, Mendelson, \& Bernstein, 1976), deviant behavior (Newcomb \& Bentler, 1988; Winters \& Henly, 1989; Belhassen \& Shani, 2012),missing work/school, nausea/vomiting, property damage, (Presley, Meilman, \& Cashin, 1993), and death (NIDA, 2015). Respondents were also given the option of "other" and were allowed to fill in their own response if a particular concern was not listed.

\section{Sample}

Survey sample. Prior to data collection, approval was granted by the Institutional Review Board (IRB) of Florida International University to conduct research involving human subjects. Multistage cluster probability sampling (Creswell, 2012) was employed to select participants for this study since a complete list of the target population was difficult to obtain. Two populations were targeted for data collection: (1) adult foodservice workers and (2) adults employed in other industries. A sample of 532 adults aged 18 and older working in the foodservice industry and other industries in the major cities of Las Vegas, Chicago, and Miami were recruited through word-of-mouth, 
university email listserve, email blasts, and social media. Participation was voluntary and confidential.

\section{Data Analysis}

Statistical Packages for Social Sciences (SPSS) Version 22 was used to analyze the data collected. Independent t-tests were conducted to find whether any significant differences existed between foodservice employees and non-foodservice employees’ drug use behaviors, experiences with drug prevention efforts, and perceived negative outcomes associated with drug use. 


\section{CHAPTER IV}

\section{RESULTS}

\section{Introduction}

This chapter shows the data analysis and the results of the study. The demographic information of the participants is described in the first section. Independent t-tests were used to analyze the data and the results of the hypotheses tested are described in the second section.

\section{Sample Profile}

The demographic profiles of the respondents are displayed in Table 1. The demographic profile of foodservice versus non-foodservice respondents are displayed in Table 2. Among the 532 respondents, 325 respondents were female (61.1 percent), 204 respondents were male (38.3 percent), and 3 respondents (0.6 percent) identified as neither male nor female. The majority of respondents were aged between 21 and 24, which represented approximately 32.7 percent. Respondents aged 25 to 34 represented 28 percent, respondents aged 35 to 44 represented 14.3 percent, respondents that were aged 18 to 20 totaled 8.8 percent, respondents that were aged 45 to 54 represented 8.3 percent, and respondents aged 55 to 64 represented 4.9 percent. The remaining 3 percent were aged 65 or older.

The majority of respondents were White, non-Hispanic, which represented 46.6 percent. Hispanic/Latino/Spanish respondents represented 28.6 percent, Black/ African American and Asian/Pacific Islander respondents both represented 10.3 percent, Native 
American/American Indian respondents represented .4 percent, and 3.8 percent of the respondents identified as "Other".

Approximately 51.7 percent of respondents had an individual annual income of between $\$ 0$ and $\$ 29,999,22.6$ percent had between $\$ 30,000$ and $\$ 59,999,10.0$ percent had between $\$ 60,000$ and $\$ 89,999,6.0$ percent had between $\$ 90,000$ and $\$ 119,999,2.4$ percent had between $\$ 120,000$ and $\$ 149,999$, and 2.6 percent reported an income of $\$ 15,000$ or more.

Educational levels were fairly high, with 88.2 percent having college experience or above. Among the remaining respondents, 6.6 percent completed high school, 2.1 percent attended vocational school or earned a GED, and .2 percent did not complete high school. 
Table 1

Demographic Profile of Respondents $(n=532)$

\begin{tabular}{|c|c|c|}
\hline Variable & $\mathbf{N}$ & Percentage (\%) \\
\hline \multicolumn{3}{|l|}{ Gender } \\
\hline Male & 204 & 38.3 \\
\hline Female & 325 & 61.1 \\
\hline Other & 3 & 0.6 \\
\hline \multicolumn{3}{|l|}{ Age } \\
\hline $18-20$ & 47 & 8.8 \\
\hline $21-24$ & 174 & 32.7 \\
\hline $25-34$ & 149 & 28.0 \\
\hline $35-44$ & 76 & 14.3 \\
\hline $45-54$ & 44 & 8.3 \\
\hline $55-64$ & 26 & 4.9 \\
\hline $65+$ & 16 & 3.0 \\
\hline \multicolumn{3}{|l|}{ Ethnicity } \\
\hline White, Non-Hispanic & 248 & 46.6 \\
\hline Hispanic/Latino/Spanish & 152 & 28.6 \\
\hline Black, African-American & 55 & 10.3 \\
\hline Native American/American Indian & 2 & 0.4 \\
\hline Asian/Pacific Islander & 55 & 10.3 \\
\hline Other & 20 & 3.8 \\
\hline \multicolumn{3}{|l|}{ Individual Annual Income } \\
\hline$\$ 0-29,999$ & 275 & 51.7 \\
\hline$\$ 30,000-\$ 59,999$ & 120 & 22.6 \\
\hline$\$ 60,000-\$ 89,999$ & 53 & 10.0 \\
\hline$\$ 90,000$ - \$119,999 & 32 & 6.0 \\
\hline$\$ 120,000$ - \$149,999 & 13 & 2.4 \\
\hline$\$ 150,000+$ & 14 & 2.6 \\
\hline N/A & 25 & 4.7 \\
\hline \multicolumn{3}{|l|}{ Education } \\
\hline College Graduate & 184 & 34.6 \\
\hline Graduate School & 116 & 21.8 \\
\hline Some College & 169 & 31.8 \\
\hline High school & 35 & 6.6 \\
\hline Vocational School & 3 & 0.6 \\
\hline Other & 6 & 1.1 \\
\hline Earned GED & 2 & 0.4 \\
\hline Did not graduate high school & 1 & 0.2 \\
\hline N/A & 16 & 3.0 \\
\hline
\end{tabular}


Table 2

Demographic Profile of Foodservice vs. Non-Foodservice Respondents $(n=532)$

\begin{tabular}{|c|c|c|}
\hline Variable & $\mathbf{N}$ & Percentage (\%) \\
\hline & Foodservice & Non-Foodservice \\
\hline Gender & & \\
\hline $\begin{array}{l}\text { Male } \\
\text { Female } \\
\text { Other }\end{array}$ & $\begin{array}{l}65(41.7 \%) \\
91(58.3 \%) \\
0\end{array}$ & $\begin{array}{c}109(37.7 \%) \\
177(61.2 \%) \\
3(.01 \%)\end{array}$ \\
\hline $\begin{array}{l}18-20 \\
21-24 \\
25-34 \\
35-44 \\
45-54 \\
55-64 \\
65+\end{array}$ & $\begin{array}{c}12(76.9 \%) \\
50(32.1 \%) \\
56(35.8 \%) \\
18(11.5 \%) \\
13(8.3 \%) \\
6(3.8 \%) \\
1(.06 \%)\end{array}$ & $\begin{array}{l}19(65.7 \%) \\
87(30.1 \%) \\
73(25.2 \%) \\
49(16.9 \%) \\
28(9.6 \%) \\
18(6.2 \%) \\
15(5.1 \%)\end{array}$ \\
\hline
\end{tabular}

\section{Ethnicity}

White, Non-Hispanic

Hispanic/Latino/Spanish

Black, African-American

Native American/American Indian

Asian/Pacific Islander

Other

$\begin{array}{cc}71(45.5 \%) & 156(54.0 \%) \\ 57(36.5 \%) & 72(24.9 \%) \\ 10(6.4 \%) & 34(11.8 \%) \\ 0 & 1(.003 \%) \\ 13(8.3 \%) & 15(5.2 \%) \\ 5(3.2 \%) & 11(3.8 \%)\end{array}$

\section{Individual Annual Income}

$\begin{array}{cc}81(51.9 \%) & 140(48.4 \%) \\ 46(29.4 \%) & 70(24.2 \%) \\ 17(10.8 \%) & 34(11.7 \%) \\ 5(3.2 \%) & 27(9.3 \%) \\ 2(1.2 \%) & 11(3.8 \%) \\ 5(3.2 \%) & 7(2.4 \%)\end{array}$

$$
\begin{aligned}
& 58(37.1 \%) \\
& 23(14.7 \%) \\
& 60(38.5 \%) \\
& 8(5.1 \%) \\
& 2(1.3 \%) \\
& 4(2.6 \%) \\
& 1(.06 \%) \\
& 0
\end{aligned}
$$

99 (34.2\%)

$81(28.0 \%)$

$89(30.8 \%)$

$16(5.5 \%)$

1 (.03\%)

$2(.06 \%)$

$1(.03 \%)$

1 (.03\%) 
The employment profiles of respondents are displayed in Table 3. The majority of respondents indicated they were employed full-time and represented 54.5 percent. Parttime employed respondents represented 26.7 percent and 18.8 percent indicated they were neither full-time nor part-time or unemployed. Among the employed respondents, the majority did not currently work in the food and beverage industry, which represented 54.3 percent, and 29.3 percent indicated they were currently working in the food and beverage industry.

Table 3

Employment Profile of Respondents $(n=532)$

\begin{tabular}{crr}
\hline Variable & N & Percentage (\%) \\
\hline Employment Status & & \\
Full-time & 290 & 54.5 \\
Part-time & 142 & 26.7 \\
Unemployed & 72 & 13.5 \\
Other & 28 & 5.3
\end{tabular}

\section{Currently Work in Food \& Beverage}

Yes

No

N/A
156

289

87
29.3

54.3

16.4 


\section{Testing of Hypotheses}

\section{Independent t-tests}

This study conducted independent t-tests to find whether any significant differences existed between foodservice employees and non-foodservice employees’ drug use behaviors, experiences with drug prevention efforts, and perceived negative outcomes associated with illicit drug use.

In order to test the first hypothesis, an independent t-test was conducted to find whether any significant difference existed between foodservice employees and nonfoodservice employees’ illicit drug use behaviors. It was hypothesized that foodservice employees use more illicit drugs than the non-foodservice labor force:

H1: Foodservice employees use illicit drugs more than the nonfoodservice labor force.

As shown in Table 4, the independent t-test at the $\mathrm{p}<.05$ level revealed a significant difference $(\mathrm{p}=.017)$ in the quality of means between foodservice and nonfoodservice employees with regards to drug use (using drugs other than those required for medical reasons). With $1=$ drug user and $2=$ non-drug user, the mean score of foodservice employees $(\mathrm{M}=1.48)$ was closer to 1 than the mean score of nonfoodservice employees $(\mathrm{M}=1.60)$. Thus, $\mathrm{H} 1$ was supported and it can be concluded that foodservice employees are more likely to use illicit drugs than the non-foodservice labor force. 
Table 4

Differences in Mean Scores for Illicit Drug Use Behaviors

Question

Foodservice

Non-Foodservice

Sig.

Have you ever used drugs other

than those required for medical

1.48

1.60

$.017 *$

reasons?

Note: Mean based on 1 = drug user, 2 = non-drug user

* = Item significant at $\mathrm{p}<0.05$

In order to test the second hypothesis, an independent t-test was conducted to find whether any significant difference existed between foodservice and non-foodservice employees’ experiences with drug prevention efforts (random drug testing). It was hypothesized that illicit drug use prevention efforts are less prominent for foodservice employees than for the non-foodservice labor force:

H2: Illicit drug use prevention efforts (e.g. random drug testing) for

foodservice employees are less prominent than for the non-foodservice labor force.

As shown in Table 5, the independent t-test at the $\mathrm{p}<.05$ level revealed a significant difference $(\mathrm{p}=.003)$ in the quality of means between foodservice and nonfoodservice employees with regards to drug prevention efforts (random drug testing). With 1 = random drug tests conducted and 2 = random drug tests not conducted, the mean score of foodservice employees $(M=1.16)$ was closer to 2 than the mean score of non-foodservice employees $(M=1.04)$. Thus, $\mathrm{H} 2$ was supported and it can be concluded that illicit drug use prevention efforts (random drug testing) are less prominent for 
foodservice employees than for the non-foodservice labor force. In other words, random drug testing is more likely to occur in other workplaces than in the foodservice industry.

Table 5

Differences in Mean Scores for Illicit Drug Use Prevention Efforts

Question

Foodservice

Non-Foodservice

Sig.

How often does your employer

conduct random drug testing?

1.16

1.04

$.003^{*}$

Note: Mean based on 1 = random drug testing conducted, 2 = random drug testing not conducted $*=$ Item significant at $\mathrm{p}<0.05$

In order to test the third hypothesis, an independent t-test was conducted to find whether a significant difference existed between foodservice and non-foodservice employees’ perceived outcome concerns associated with illicit drug use. Responses on each extreme end ( 1 = not concerned and $5=$ very concerned) were used to analyze the data and eliminate ambiguous answers. Drug users tend be high-sensation seekers and relate more closely to extremes (Konkel, 2009). Any response to this question that was a 2, 3, or 4 were not calculated. It was hypothesized that there are more short-term outcome concerns regarding illicit drug use among foodservice employees as compared to the nonfoodservice labor force:

H3: There are more short-term outcome concerns regarding drug use among foodservice employees than the non-foodservice labor force.

As shown in Table 6, the mean score of foodservice employees was significantly different than non-foodservice employees for the short-term outcome concerns "making 
bad choices” (1.55 vs. 1.41), "paranoia” (1.43 vs. 1.30), “legal issues” (1.61 vs. 1.48), "lethargy” (1.49 vs. 1.33), "less productive” (1.54 vs. 1.32), and "physical appearance harmed" (1.49 vs. 1.36$)$ with $1=$ not concerned and $2=$ very concerned. Thus, H3 was supported and the results indicated foodservice employees recognized more short-term negative outcomes (e.g. lethargy) than the non-foodservice labor force. Foodservice employees were more concerned with making bad choices, their physical appearance changing, legal problems, and becoming paranoid, lethargic, and less productive as a result of illicit drug use. 
Table 6

Differences in Mean Scores for Illicit Drug Use Outcome Concerns

\begin{tabular}{|c|c|c|c|}
\hline Outcome Concern & Foodservice & Non-Foodservice & Sig. \\
\hline Anxiety & 1.35 & 1.27 & .279 \\
\hline Addiction & 1.50 & 1.40 & .131 \\
\hline Withdrawals & 1.37 & 1.31 & .344 \\
\hline Job Loss & 1.56 & 1.49 & .249 \\
\hline Loss of Focus & 1.48 & 1.35 & .068 \\
\hline Bad Choices & 1.55 & 1.41 & $.049 *$ \\
\hline Dangerous Situations & 1.53 & 1.43 & .114 \\
\hline Overdose & 1.40 & 1.39 & .416 \\
\hline Paranoia & 1.43 & 1.30 & $.036 *$ \\
\hline Legal & 1.61 & 1.47 & $.051 *$ \\
\hline Lethargy & 1.49 & 1.33 & $.019 *$ \\
\hline Birth Defects & 1.40 & 1.36 & .534 \\
\hline Less Productive & 1.54 & 1.32 & $.002 *$ \\
\hline Financial Burden & 1.50 & 1.40 & .177 \\
\hline Fear of Overdose & 1.45 & 1.37 & .259 \\
\hline Health Problems & 1.56 & 1.48 & .246 \\
\hline Hangover & 1.37 & 1.29 & .263 \\
\hline Loss of Friends & 1.43 & 1.37 & .441 \\
\hline Hallucinations & 1.36 & 1.30 & .361 \\
\hline Sexual Assault & 1.38 & 1.32 & .270 \\
\hline Anger & 1.42 & 1.36 & .369 \\
\hline Physical Appearance & 1.49 & 1.35 & $.042 *$ \\
\hline Conflict & 1.49 & 1.41 & .242 \\
\hline Damaged Reputation & 1.57 & 1.46 & .108 \\
\hline Injury & 1.43 & 1.35 & .241 \\
\hline Immoral & 1.40 & 1.41 & .856 \\
\hline Bad Batch & 1.47 & 1.41 & .399 \\
\hline Domestic Abuse & 1.37 & 1.34 & .673 \\
\hline Weight Change & 1.43 & 1.34 & .196 \\
\hline Career Indecision & 1.45 & 1.35 & .160 \\
\hline Deviant Behavior & 1.40 & 1.34 & .384 \\
\hline Goals Uncertain & 1.40 & 1.35 & .412 \\
\hline Missing Work & 1.45 & 1.40 & .456 \\
\hline Nausea & 1.39 & 1.30 & .206 \\
\hline Property Damage & 1.36 & 1.28 & .173 \\
\hline Death & 1.48 & 1.47 & .853 \\
\hline Other & $\begin{array}{l}1.40 \\
1.34\end{array}$ & 1.17 & .060 \\
\hline
\end{tabular}

Note: Mean based on 1 = not concerned, 2 = very concerned

* = Item significant at $\mathrm{p}<0.05$ 


\section{Summary}

Foodservice employees are more likely to use illicit drugs than those working in other industries. Illicit drug use prevention efforts, such as random drug testing are less prominent in the foodservice industry than in other workplaces. Foodservice workers were found to be more concerned with short-term negative outcomes, such as becoming

lethargic, paranoid, and less productive, rather than considering long-term effects as a result of illicit drug use. 


\section{CHAPTER V}

\section{DISCUSSION}

\section{Introduction}

The primary purpose of this study and results of the hypotheses testing were interpreted and discussed in the following chapter. Based on the findings, practical implications for the foodservice industry are provided. Several limitations of this study and future research recommendations are also discussed.

\section{Discussion of Results}

The primary purpose of this study was to further explore illicit drug use behaviors and experiences among adults working in the foodservice industry as compared to the non-foodservice labor force. More specifically, this study attempted to quantitatively analyze the findings from a previous study (Kitterlin et al., 2016) to provide a more thorough examination of the illicit drug use phenomenon in the foodservice industry. Independent t-tests indicated significant differences in illicit drug use behaviors, experiences with drug use prevention efforts, and perceived negative outcomes associated with drug use between foodservice and non-foodservice employees. Ergo, all three hypotheses were supported.

Foodservice employees indicated a higher rate of illicit drug usage than nonfoodservice employees in this study. These results are consistent with the findings of numerous research that suggest illicit drug use is more prevalent in the foodservice industry than any other industry (Belhassen \& Shani, 2012; Bush \& Lipari, 2015; “Drug 
use highest in foodservice”, 2007; Fricke, 2015; Frone, 2006; Kitterlin et al., 2015;

Kitterlin et al., 2016; Murray, 2009; Romeo, 2015; Substance Abuse and Mental Health Services Administration, 2009a, 2011, 2012, 2013, 2016; Zhu et al., 2010; Zuber, 1997). Moreover, respondents in this study who were aged between 18 and 24 made up the majority of the sample population at 41.5 percent, which also mimics the relatively young labor pool of workers that make up a large portion of foodservice employees (Belhassen \& Shani, 2012). These results are consistent with previous research that found young adults aged 18-24 had the highest rates of drug and alcohol abuse (National Institute on Alcohol Abuse and Alcoholism, 2008) and were the biggest abusers of prescription drugs (National Institute on Drug Abuse, 2016). It is interesting to note that while previous research has found males to be more likely than females to abuse drugs and alcohol (Mayo Clinic, 2014; NIAAA, 2008; SAMHSA, 2016), females represented 61.1 percent of this study's population which made up the majority of the sample. Although specific drug types were not investigated in this current study, the Centers for Disease Control and Prevention declared heroin use is on the rise among women and may be something to consider in future research. These results provide further evidence that illicit drug use is not only rampant in the foodservice industry but among young adults, as well. Aggressive efforts should be made by industry professionals and society as a whole to mitigate this precarious problem.

Illicit drug use prevention efforts were found to be less prominent for foodservice employees than the non-foodservice labor force. Foodservice employees indicated their current employer does not conduct random drug testing which significantly differed from their non-foodservice counterparts' random drug testing experiences. These results may 
provide further evidence that lenient attitudes towards drug using behaviors still exist (among management and employees); results echo the findings of previous research which suggested that, aside from a brief mention in the employee handbook, drug policies are not strongly enforced in the foodservice work environment (Kitterlin et al., 2016). Moreover, these results are also consistent with a national study that revealed preemployment drug testing rates (42.9 percent) were higher than random drug testing rates (29.6 percent) for full-time employees working in all industries across the United States (Hickox, 2012).

While there was no significant difference found in pre-employment drug testing procedures between foodservice and non-foodservice employees, it may stand to reason that pre-employment drug testing may likely be a standard occurrence across all industries. Although drug policies are known to be much more stringent in safetysensitive occupations such as truck drivers and pilots, the foodservice industry has not altogether eliminated drug use prevention efforts. As mentioned in Kitterlin and Moreo (2012), the foodservice industry has adopted pre-employment drug testing as a means of deterring against illicit drug use, which may suffice for many foodservice employers and replace the need for any further drug testing once the applicant is hired. However, applicants are generally informed of the pre-employment drug test which presumably allows the individual to "prepare" for the test so they can pass it. Moreover, with illicit drug use deeply embedded in the work culture (Bourdain, 2007; Kitterlin et al., 2015; Kitterlin et al., 2016; Kjaerheim et al., 1995; Kjaerheim et al., 1996; Larsen, 1994; Zhu et al., 2011), one can safely assume random drug tests are not often conducted primarily due to cost and the increased likelihood of multiple failures. 
Findings of this study also revealed foodservice employees were more concerned with short-term negative outcomes than the non-foodservice labor force as a result of illicit drug use. Foodservice employees recognized short-term outcomes; making bad choices, a change in their physical appearance, legal issues, paranoia, lethargy, and a decrease in productivity were among foodservice employees' concerns regarding illicit drug use. These results are consistent with previous research findings which proposed long-term adverse effects of illicit drug use were not taken into serious consideration by foodservice employees (Kitterlin et al., 2016).

It comes as no surprise that short-term outcomes were at the forefront of trepidation. As previous literature suggests, younger individuals crave instant gratification (Eisner, 2005) and tip-earning foodservice workers have more accessibility to cash (Zhu et al., 2010) which increases the likelihood to purchase goods for “immediate enjoyment” (Wertenbroch, Soman, \& Nunes, 2002, as cited in Zhu et al., 2010). Thus, it is presumed that young adults working in the foodservice industry have a greater tendency to neglect the future. Moreover, both foodservice workers and drug users have the propensity to be impulsive (Ersche et al., 2010; Kane, 2013; Terracciano et al., 2004); impulsivity is defined as the "predisposition toward rapid, unplanned reactions to internal or external stimuli with diminished regard to the negative consequences of these reactions to the impulsive individual or to others” (Chamberlain \& Sahakian, 2007, as cited in Chamorro et al., 2012, p.2) which may further support this claim. 


\section{Implications}

The results of this study may offer practical implications for foodservice industry professionals. Research findings continue to reveal the prevalence of illicit drug use in the foodservice industry. Illicit drug use has been, and continues to be, an ongoing problem with no permanent solution in sight. As discussed in Kitterlin et al. (2016), in order to reduce illicit drug use behaviors among workers in the foodservice industry more emphasis needs to be placed on understanding the seriousness of this phenomenon. As mentioned earlier in the manuscript, the United States workforce experienced an \$81 billion loss in productivity as a result of problem behavior associated with illicit drug use (Belhassen \& Shani, 2012). Additionally, workplace safety, attendance, and service quality may become jeopardized by employee illicit drug use which can adversely affect profit margins (DiNardo, 1994; French et al., 1995; Frone, 2004; Larsen, 1994; Martin et al., 1994; Zhu et al., 2010). Moreover, a variety of adverse health effects such as heart disease or failure, mental illness or even death are more likely to occur with illicit drug usage.

It is suggested that management take a more active role in combating illicit drug usage among employees. Since drug use is already established as a workplace norm (Bourdain, 2007; Kitterlin et al., 2015; Kitterlin et al., 2016; Kjaerheim et al., 1995;

Kjaerheim et al., 1996; Larsen, 1994; Zhu et al., 2011), steps should be taken to modify this perception so that it becomes an unacceptable behavior. Kitterlin et al. (2016) proposed leading by example and demonstrating drug-free behaviors are steps management can take towards setting a new tone in the workplace. Moreover, healthy 
business practices provide guests and business assets with protection, which Murray (2009) proposes may help reduce the chances of any legal action being taken against the organization.

Management may also want to take employee morale into consideration. Mangione and Quinn (1975) found that job satisfaction was significantly related to illicit drug use. Employees who enjoy their job may be less likely to jeopardize it. Positive workplace behavior such as providing outstanding customer service or increasing sales should be recognized; rewards or incentive programs should be offered to employees as a means of boosting overall morale. Employees who feel appreciated will more likely avoid engaging in problem behaviors such as drug use (Heskett, Jones, Loveman, Sasser, \& Schlesinger, 2008; Reisel, Probst, Chia, Maloles, \& Konig, 2010).

It is pertinent for an organization to enforce a drug-free workplace in order for changes in employee drug use to occur. Drug policies need to be more apparent in the workplace; a blurb in the employee handbook (Kitterlin et al., 2016) may not be sufficient in preventing employee drug use. Drug-free work zone and zero tolerance signs could be placed around the establishment for everyone to see. Management may want to consider implementing a zero tolerance policy and more random drug testing. However, there must be appropriate repercussions (e.g. job termination) if an employee tests positive for an illicit substance. Since drugs were found to be easily accessible in the workplace (Kitterlin et al., 2016; Zhu et al., 2010), appropriate disciplinary action needs to be taken if an employee is found with illicit drugs in their possession or using illicit drugs at work in order to discourage this type of behavior. Kitterlin et al. (2016) also 
proposed daily or random searches of employees and their personal belongings to screen for illicit drugs, or prohibiting personal belongings (e.g. backpack) all together from being brought in to work.

An important finding of this study was that foodservice employees were more concerned with short-term negative outcomes regarding illicit drug use. In order for management to get through to employees, they must speak in terms they understand. Kitterlin et al. (2016) proposed playing upon the apprehension of short-term side effects that may occur, instead of belaboring the long term consequences of illicit drug use. It may be more effective to emphasize that feeling lethargic is not as temporary as it may seem; there are a series of events that may follow such as botching an order or providing terrible customer service which could amount to a more serious consequence such as job loss (Kitterlin et al., 2016). This strategy may help foodservice employees redirect their interim focus to the future.

\section{Limitations}

As with all research, there were several limitations to this study. Due to a combination of probability and non-probability sampling approaches, generalizations of the findings could not be made. Participant demographics may have been limited by the sampling method used. The majority of participants were college educated and did not currently work in the foodservice industry, and the sample was not evenly distributed between males and females, so the data may not portray an accurate representation of the target population. Another limitation to this study is that the central focus is a sensitive topic (illicit drug use). Since participants are self-reporting on an illegal activity, their 
responses may not be entirely truthful. Finally, the survey instrument was somewhat flawed so some of the questions may not have been as clear to the participants of this study.

\section{Future Research}

Future research should be conducted with a larger sample size to generalize the findings of the current study. It is also recommended that modifications are made to the survey instrument. Additional research could compare employment levels such as management versus hourly employees. Future studies could expand upon employees’ outcome concerns regarding illicit drug use by comparing foodservice employees to employees employed in a specific industry or comparing the outcome concerns of male and female foodservice employees. Future studies could also explore drug use behaviors of females and males working in the foodservice industry. Additional research could further examine the relationship between intelligence and drug use within the foodservice industry or other occupational industries. Future studies exploring various drug prevention efforts and their effectiveness on reducing or eliminating workplace illicit drug use may also be considered.

\section{Summary}

Significant findings of the current study were established and all hypotheses were supported. Results of this study indicated foodservice employees were more likely to use illicit drugs than employees working in other industries. Drug use prevention efforts were also found to be less prominent for foodservice employees than the non-foodservice labor force. Data also revealed foodservice employees were more 
concerned with short-term negative outcomes than the non-foodservice labor force as a

result of illicit drug use. Replication of this study with a larger, representative sample and a modified data collection method is recommended. 


\section{REFERENCES}

Ames, G. M., Grube, J. W., \& Moore, R. S. (2000). Social control and workplace drinking norms: a comparison of two organizational cultures. Journal of studies on alcohol, 61(2), 203-219.

Bacharach, S. B., Bamberger, P., \& Biron, M. (2010). Alcohol consumption and workplace absenteeism: the moderating effect of social support. Journal of Applied Psychology, 95(2), 334.

Bacharach, S. B., Bamberger, P. A., \& Sonnenstuhl, W. J. (2002). Driven to drink: Managerial control, work-related risk factors, and employee problem drinking. Academy of Management Journal, 45(4), 637-658.

Belhassen, Y., \& Shani, A. (2012). Hotel workers' substance use and abuse. International Journal of Hospitality Management, 31(4), 1292-1302.

Bennett, J. B., Aden, C. A., Broome, K., Mitchell, K., \& Rigdon, W. D. (2010). Team resilience for young restaurant workers: research-to-practice adaptation and assessment. Journal of Occupational Health Psychology, 15(3), 223.

Bennett, J. B., \& Lehman, W. E. (1999). The relationship between problem co-workers and quality work practices: A case study of exposure to sexual harassment, substance abuse, violence and job stress. Work \& stress, 13(4), 299-311.

Blanchard, K. A., Morgenstern, J., Morgan, T. J., Lobouvie, E. W., \& Bux, D. A. (2003). Assessing consequences of substance use: psychometric properties of the inventory of drug use consequences. Psychology of Addictive Behaviors, 17(4), 328.

Bon, S. (2014, March 28). IQ and Drug Use. Retrieved from https://www.thefix.com/content/iq-and-drug-use

Bonn, M. A., \& Forbringer, L. R. (1992). Reducing turnover in the hospitality industry: an overview of recruitment, selection and retention. International Journal of Hospitality Management, 11(1), 47-63.

Bourdain, A. (2007). Kitchen confidential updated edition: Adventures in the culinary underbelly. Ecco.

Bush, D. \& Lipari, R. (April 16, 2015). The CBHSQ Report: Substance Use and Substance Use disorder, by Industry. Substance Abuse and Mental Health Services Administration, Center for Behavioral Health Statistics and Quality. Rockville, MD. 
Bywood, P., Pidd, K., \& Roche, A. (2006). Illicit drugs in the Australian Workforce: Prevalence and patterns of use. Workforce, 4, 2.

Centers for Disease Control and Prevention (CDC). (2016). Injury Prevention \& Control: Opiod Overdose. Retrieved from http://www.cdc.gov/drugoverdose/opioids/heroin.html

Chamorro, J., Bernardi, S., Potenza, M. N., Grant, J. E., Marsh, R., Wang, S., \& Blanco, C. (2012). Impulsivity in the general population: a national study. Journal of psychiatric research, 46(8), 994-1001.

Creswell, J.W. (2012). Planning, conducting, and evaluating quantitative and qualitative research ( $4^{\text {th }}$ ed.). Boston, MA: Pearson Education Inc.

Degenhardt, L., \& Hall, W. (2012). Extent of illicit drug use and dependence, and their contribution to the global burden of disease. The Lancet, 379(9810), 55-70.

DiNardo, J. (1994). A critical review of the estimates of the costs of alcohol and drug use. In Drug testing in the workplace (pp. 57-76). Springer US.

Drug-Free Workplace Act (n.d.). HR Hero. Retrieved from http://topics.hrhero.com/drugfree-workplace-act/

Drug-Free Workplace Act, 41 U.S.C. 701 (1988).

Drug use highest in foodservice. (2007). In Nation's Restaurant News. Retrieved from http://nrn.com/corporate/drug-use-highest-foodservice-new-study-finds

Effects of stimulants. (n.d.) in Stimulants.com. Retrieved from http://stimulants.com/effects-of-stimulants/

Eisner, S. P. (2005). Managing generation Y. SAM Advanced Management Journal, 70(4), 4.

Ersche, K. D., Turton, A. J., Pradhan, S., Bullmore, E. T., \& Robbins, T. W. (2010). Drug addiction endophenotypes: impulsive versus sensation-seeking personality traits. Biological psychiatry, 68(8), 770-773.

Executive Order No. 12564, 51 Fed. Reg. 32889, 3 C.F.R. 224 (1986).

Ferner, M. (2014, May 20). Prehistoric people liked to drink alcohol and do drugs, but probably for religious reasons. The Huffington Post. Retrieved from http://www.huffingtonpost.com/2014/05/20/even-cavemen-liked-toget_n_5316914.html 
French, M. T., Zarkin, G. A., Hartwell, T. D., \& Bray, J. W. (1995). Prevalence and consequences of smoking, alcohol use, and illicit drug use at five worksites. Public Health Reports, 110(5), 593.

Fricke, P. (2015, June 17). Study: Drug abuse startlingly common in food service, construction. The Daily Caller. Retrieved from http://dailycaller.com/2015/06/17/study-drug-abuse-startlingly-common-in-foodservice-construction/

Frone, M. R. (2004). Alcohol, drugs, and workplace safety outcomes: A view from a general model of employee substance use and productivity. The psychology of workplace safety, 127-156.

Frone, M. R. (2006). Prevalence and distribution of illicit drug use in the workforce and in the workplace: Findings and implications from a US National survey. Journal of Applied Psychology, 91(4), 856.

Frone, M.R. (2013). Alcohol and illicit drug use in the workforce and workplace. Washington, DC: American Psychological Association.

Gahlinger, P. (2004). Illegal drugs. New York, NY: Penguin.

Goleman, D. P. (1995). Emotional intelligence: Why it can matter more than IQ for character, health and lifelong achievement.

Greenberg, I., Kuehnle, J., Mendelson, J. H., \& Bernstein, J. G. (1976). Effects of marihuana use on body weight and caloric intake in humans.

Psychopharmacology, 49(1), 79-84.

Guerra-Doce, E. (2015). The origins of inebriation: archaeological evidence of the consumption of fermented beverages and drugs in prehistoric Eurasia.Journal of Archaeological Method and Theory, 22(3), 751-782.

Heskett, J. L., Jones, T. O., Loveman, G. W., Sasser, W. E., \& Schlesinger, L. A. (2008). Putting the service-profit chain to work. Harvard Business Review.

Hickox, S. A. (2012). Drug testing of medical marijuana users in the workplace: an inaccurate test of impairment. Hofstra Lab. \& Emp. LJ, 29, 273.

Horgan, C., Skwara, K. C., Strickler, G., \& Andersen, L. (2004). Substance abuse: The nation's number one health problem. Diane Publishing Company. 
Industry must take steps to detect and discourage employee drug use. (1997, March 10). Nation's Restaurant News, Retrieved from Hospitality \& Tourism Complete database.

Iverson, R. D., \& Deery, M. (1997). Turnover culture in the hospitality industry. Human Resource Management Journal, 7(4), 71-82.

Kandel, D. B. (Ed.). (1978). Longitudinal research on drug use: Empirical findings and methodological issues (pp. 3-38). Washington, DC: Hemisphere Publishing Corporation.

Kane, M. (2013, March 18). The heat of the kitchen: Addiction among chefs. Huffpost Living. Retrieved from http://www.huffingtonpost.ca/marion-kane/chefsaddiction_b_2900645.html

Khanmohammadi, A., Homayouni, A., Amiri, S. M., \& Nikpour, G. A. (2009). P01-43 Low emotional intelligence as a predictor of tendency to addiction.European Psychiatry, 24, S431.

Kitterlin, M., Curtis, C., \& Cervera, A. (2015). Workplace substance use and acceptance among nightclub employees: A qualitative investigation. Tourism Analysis: An Interdisciplinary Journal, 20(5).

Kitterlin, M., Moll, L., \& Kaminski, K. (2016). A comparative exploration of illicit drug use inside and out of the foodservice industry. Manuscript submitted for publication (copy on file with author).

Kitterlin, M. \& Moreo, P. (2012). Pre-employment drug-testing in the full-service restaurant industry and its relationship to employee work performance factors. Journal of Human Resources in Hospitality and Tourism, 11(1), 36-51.

Kjaerheim, K., Mykletun, R., Aasland, O., Haldorsen, T. and Anderson, A. (1995). Heavy drinking in the restaurant business: The role of social modeling and structural factors of the workplace. Addiction, 90(11), 1487-1495.

Kjaerheim, K., Mykletun, R., and Haldorsen, T. (1996). Selection into the restaurant business based on personality characteristics and the risk of heavy drinking. Personality and Individual Differences, 21(4), 625-629.

Konkel, L. (2009, July 13). Extreme Psychology. Retrieved from http://scienceline.org/2009/07/health-konkel-extreme-sports-risk-psychology/

Kotov, R., Gamez, W., Schmidt, F., \& Watson, D. (2010). Linking “big” personality traits to anxiety, depressive, and substance use disorders: a metaanalysis. Psychological bulletin, 136(5), 768. 
Kuhn, C., Swartzwelder, S., \& Wilson, W. (2008).Buzzed: The straight facts about the most used and abused drugs from alcohol to ecstasy. WW Norton \& Company.

Kun, B., \& Demetrovics, Z. (2010). Emotional intelligence and addictions: a systematic review. Substance use \& misuse, 45(7-8), 1131-1160.

Larsen, S. (1994). Alcohol use in the service industry. Addiction, 89(6), 733-741.

Leigh, J. P., \& Jiang, W. Y. (1993). Liver cirrhosis deaths within occupations and industries in the California Occupational Mortality Study. Addiction, 88(6), 767.

Madan, A., Beech, D. J., \& Flint, L. (2001). Drugs, guns, and kids: the association between substance use and injury caused by interpersonal violence. Journal of pediatric surgery, 36(3), 440-442.

Mandell, W., Eaton, W. W., Anthony, J. C., \& Garrison, R. (1992). Alcoholism and occupation: A review and analysis of 104 occupations. Alcoholism: Clinical and Experimental Research, 16(4), 734-746.

Mangione, T.W., \& Quinn, R.P. (1975). Job satisfaction, counterproductive behavior, and drug use at work. Journal of Applied Psychology, 60(1), 114; 114-116; 116.

Manoj Sharma, M. B. B. S. (2012). The relationship between emotional intelligence and abuse of alcohol, marijuana, and tobacco among college students. Journal of Alcohol and Drug Education, 56(1), 8.

Martin, J. K., Kraft, J. M., \& Roman, P. M. (1994). Extent and impact of alcohol and drug use problems in the workplace. In Drug Testing in the Workplace (pp. 331). Springer US.

Mayer, J. D., Salovey, P., \& Caruso, D. R. (2004). Emotional intelligence: theory, findings, and implications. Psychological Inquiry, 15(3), 197-215.

Mayo Clinic. (2014, December 5). Drug Addiction: Risk factors. Retrieved from http://www.mayoclinic.org/diseases-conditions/drug-addiction/basics/riskfactors/con-20020970

Moore, R. S., Ames, G. M., Duke, M. R., \& Cunradi, C. B. (2012). Food service employee alcohol use, hangovers and norms during and after work hours. Journal of substance use, 17(3), 269-276.

Murray, C. (2009, October 13). The drinking dilemma. Hotel Interactive. Retrieved from http://www.hotelinteractive.com/article.aspx?articleid=15139

National Drug-Free Workplace Alliance (NDWA). (2007). About Us. Retrieved from http://www.ndwa.org/aboutus.php 
National Institute on Alcohol Abuse and Alcoholism (NIAAA). (2008). Alcohol and other drugs. Retrieved from

http://pubs.niaaa.nih.gov/publications/AA76/AA76.htm

National Institute on Drug Abuse (NIDA). (n.d.). About drug abuse: Magnitude. Retrieved from http://archives.drugabuse.gov/about/welcome/aboutdrugabuse/magnitude/

National Institute on Drug Abuse (NIDA). (2014). How do stimulants affect the brain and body? Retrieved from https://www.drugabuse.gov/publications/researchreports/prescription-drugs/stimulants/how-do-stimulants-affect-brain-body

National Institute on Drug Abuse (NIDA). (2015). Nationwide Trends. Retrieved from http://www.drugabuse.gov/publications/drugfacts/nationwide-trends

National Institute on Drug Abuse (NIDA). (2016). Abuse of Prescription Drugs Affects Young Adults Most. Retrieved from https://www.drugabuse.gov/relatedtopics/trends-statistics/infographics/abuse-prescription-rx-drugs-affects-youngadults-most

National Institute on Drug Abuse (NIDA). (2016). What are the short-term effects of cocaine use? Retrieved from https://www.drugabuse.gov/publications/researchreports/cocaine/what-are-short-term-effects-cocaine-use

National Restaurant Association. (2016). Facts at a glance. Retrieved from http://www.restaurant.org/News-Research/Research/Facts-at-a-Glance.

National Survey on Drug Use and Health (NSDUH). (2010). Results from the 2010 national survey on drug use and health: Summary of national findings. Retrieved from http://www.samhsa.gov/data/NSDUH/2k10NSDUH/2k10Results.htm.

Newcomb, M.D. \& Bentler, P.M. (1988). Consequences of adolescent drug use: Impact on the lives of young adults. Sage Publications, Inc.

Pidd, K., Roche, A. M., \& Buisman-Pijlman, F. (2011). Intoxicated workers: findings from a national Australian survey. Addiction, 106(9), 1623-1633.

Poole, R. \& Brabbins, C. (1996). Drug induced psychosis. British Journal of Psychiatry, (168), 135-138.

Presley, C. A., Meilman, P. W. \& Cashin, J. R. (1993). Alcohol and Drugs on American College Campuses: Use, Consequences, and Perceptions of the Campus Environment, 4, 1992-94. Carbondale, IL: Core Institute, Southern Illinois University. 
Quest Diagnostics. (2012). The Drug Testing Index. Retrieved from https://www.questdiagnostics.com/dms/Documents/DTI-Reports/2012-0313_DTI.pdf

Reisel, W. D., Probst, T. M., Chia, S. L., Maloles, C. M., \& König, C. J. (2010). The effects of job insecurity on job satisfaction, organizational citizenship behavior, deviant behavior, and negative emotions of employees.International Studies of Management \& Organization, 40(1), 74-91.

Riley, H., \& Schutte, N. S. (2003). Low emotional intelligence as a predictor of substance-use problems. Journal of drug education, 33(4), 391-398.

Romeo, P. (2015). Study finds drug abuse highest in hospitality. Restaurant Business. Retrieved from: http://www.restaurantbusinessonline.com/news/study-finds-drug-abusehighest hospitality

Shierholz, H. (2014, August 21). Low wages and few benefits mean many restaurant workers can’t make ends meet. Economic Policy Institute. Retrieved from http://www.epi.org/publication/restaurant-workers/.

Skinner, H.A. (1982). DAST-20. Department of Health Sciences, University of Toronto.

Spector, A. (2001, May 21). A career in foodservice: Unhealthy lifestyle. Nation's Restaurant

News.

Substance Abuse \& Mental Health Services Administration (SAMHSA). (2009a). Current illicit drug and heavy alcohol use by occupation. Retrieved from http://www.oas.samhsa.gov/occupation.htm

Substance Abuse and Mental Health Services Administration (SAMHSA). (2011). Results from the 2010 National Survey on Drug Use and Health: Vol. I. Summary of national findings, (Center for Behavioral Health Statistics and Quality, NSDUH Series H 41, HHS Publication No. SMA 11 4658). Rockville, MD: SAMHSA.

Substance Abuse \& Mental Health Services Administration (SAMHSA). (2012). The scope of substance abuse in America. Retrieved from http://www.samhsa.gov/prevention/nationalpreventionmonth/\#foot-5

Substance Abuse and Mental Health Services Administration. (2013). Results from the 2012 National Survey on Drug Use and Health: Summary of National Findings, 
NSDUH Series H-46, HHS Publication No. (SMA) 13-4795. Rockville, MD: Substance Abuse and Mental Health Services Administration, 2013.

Substance Abuse and Mental Health Services Administration. (2015). Results from the 2014 National Survey on Drug Use and Health (HHS Publication No. SMA 154927, NSDUH Series H-50). Retrieved from http://www.samhsa.gov/data/sites/default/files/NSDUH-FRR1-2014/NSDUHFRR1-2014.pdf

Substance Abuse and Mental Health Services Administration. (2016). Results from the 2015 National Survey on Drug Use and Health (HHS Publication No. SMA 164984, NSDUH Series H-51). Retrieved from http://www.samhsa.gov/data/

Stinson, F.S., DeBakey, S.F., \& Steffens, R.A. (1992). Prevelance of DSM-III-R alcohol abuse and/or dependence among selected occupations: United States, 1988. (Diagnostic and Statistical Manual of Mental Disorders ( $3^{\text {rd }}$ ed.), Revised). Alcohol Health \& Research World, 16(2), 165-173.

Terracciano, A., Löckenhoff, C. E., Crum, R. M., Bienvenu, O. J., \& Costa, P. T. (2008). Five-

Factor Model personality profiles of drug users. Bmc Psychiatry, 8(1), 1.

U.S. Census Bureau. (2012). Labor Force, Employment, and Earnings. Statistical Abstract of the United States, 387.

U.S. Census Bureau. (2013). Income and Poverty in the United States. U.S. Department of Commerce. Retrieved from https://www.census.gov/content/dam/Census/library/publications/2014/demo/p60249.pdf

U.S. Department of Labor. (2015, May). Industries at a glance. Retrieved from http://www.bls.gov/iag/tgs/iag72.htm\#earnings

Volkow, N. (2014, May 14). America's addiction to opiods: Heroin and prescription drug abuse. Retrieved from https://www.drugabuse.gov/about-nida/legislativeactivities/testimony-to-congress/2016/americas-addiction-to-opioids-heroinprescription-drug-abuse

Weber, L. (2016, September 14). Greater share of U.S. workers testing positive for illicit drugs. The Wall Street Journal. Retrieved from http://www.wsj.com/articles/greater-share-of-u-s-workers-testing-positive-forillicit-drugs-1473901202 
White, J., \& Batty, G. D. (2011). Intelligence across childhood in relation to illegal drug use in adulthood: 1970 British Cohort Study. Journal of epidemiology and community health, jech-2011.

White, J. W., Gale, C. R., \& Batty, G. D. (2012). Intelligence quotient in childhood and the risk of illegal drug use in middle-age: the 1958 National Child Development Survey. Annals of epidemiology, 22(9), 654-657.

Williams, L. (1986, November 29). Reagan drug testing plan to start despite court rulings opposing it. The New York Times. Retrieved from http://www.nytimes.com/1986/11/29/us/reagan-drug-testing-plan-to-startdespite-court-rulings-opposing-it.html

Winter, K.C. \& Henly, G.A.(1989). Personal Experience Inventory test and manual. Los Angeles: Western Psychological Services.

Zagat. (2016, January, 26). The state of American dining in 2016. Retrieved from https://www.zagat.com/b/the-state-of-american-dining-in-2016

Zhiwei, Z., \& Snizek, W.E. (2003). Occupation, job characteristics, and the use of alcohol and other drugs. Social Behavior and Personality: An International Journal, 31 (4), 395.

Zhu, J. (2008). Alcohol and illicit substance use in the food service industry: Assessing self-selection and job-related risk factors. (Master's thesis). Retrieved from OhioLINK ETD Center. (osu1221974238).

Zhu, J., Tews, M. J., Stafford, K., \& George, R. T. (2010). Alcohol and illicit substance use in the food service industry: Assessing self-selection and job-related risk factors. Journal of Hospitality \& Tourism Research.

Zuber, A. (1997, February 17). Restaurant workers worst drug abusers. Nation's Restaurant News, 31(7), 1. Retrieved from Hospitality \& Tourism Complete database. 